\title{
Nipah Virus: A Novel Emerging Zoonotic Disease
}

Rajinder M Joshi

Al Borg Medical Laboratories, Sharq, Kuwait

*Corresponding author: Rajinder M Joshi, Senior Consultant, Microbiologist and Medical Director, Al Borg Medical Laboratories, Sharq, Kuwait, Tel: 00965-66142348; E-mail: drrmjoshi2002@yahoo.com

Received date: June 21, 2018; Accepted date: June 30, 2018; Published date: July 06, 2018

Copyright: $@ 2018$ Joshi RM. This is an open-access article distributed under the terms of the Creative Commons Attribution License, which permits unrestricted use, distribution, and reproduction in any medium, provided the original author and source are credited.

\section{Editorial}

Nipah virus $(\mathrm{NiV})$ derives its name from Kampung Sungai Nipah; a village in Malaysia from where it was first reported in 1998-1999 [1].The virus comes under Henipavirus (a relatively new genus) in the subfamily Paramyxovirinae. NiV is closely related to two other bat borne viruses, the Hendra virus which is highly pathogenic and often fatal to horses and other mammals including humans and the Cedar virus which is generally considered non-pathogenic. $\mathrm{NiV}$ is a single stranded negative sense RNA virus, pleomorphic ranging from 40 to $600 \mathrm{~nm}$ in diameter covered by a lipid bilayer envelope. The virus has three important internal proteins, the Nucleocapsid proteins $(\mathrm{N})$, Phosphoproteins ( $\mathrm{P}$ ) and large polymerase proteins (L). The envelope has two types of spikes called Fusion proteins $(\mathrm{F})$ and receptor-binding Glycoproteins $(\mathrm{G})$. While fusion proteins are responsible for fusion of viral membrane with the host cell membrane enabling release of viral contents into the cell, the glycoproteins generally bind to Ephrin B2 surface proteins but are also capable of binding to some other receptors as well. The Matrix proteins (M) present on the inner surface of lipid bilayer are responsible for the structural integrity and the budding of virus particles. In addition, three other proteins, $\mathrm{C}, \mathrm{V}$ and $\mathrm{W}$ are involved in the transcription and replication of the virus in the host cells. While frugivorous (fruit eating) bats of Pteropus genus are the main natural reservoir hosts of the virus, some other species of fruit bats may also carry the virus and at times even insectivorous (insect eating) bats may also be harbouring the virus. In nature, the virus is maintained in bats-pigs cycle. Pigs act as intermediate and amplifier hosts. In addition to pigs, other animals like cats, dogs, goats and horses have also been shown to be positive for anti-NiV antibodies, but their role in transmitting NiV infection in humans has not been established. The bats themselves usually do not manifest symptoms of virus infection but they pass on infection to pigs or humans. The bats shed the virus in their secretions and excretions. The humans acquire infection by coming in contact with bat excreta or saliva or consuming partially eaten or licked fruits by bats. Once the virus is transmitted to pigs, they are highly infectious to other pigs and humans. Pigs manifest respiratory and neurologic symptoms and present with a typical barking cough which is recognised as a tell-tale sign of $\mathrm{NiV}$ infection in pigs. Although the $\mathrm{NiV}$ is highly virulent and contagious to pigs but the mortality in pigs is only about $1-5 \%$. Pig farmers may acquire infection by direct and indirect contact with pigs, usually through respiratory secretions or infected pig tissues. However, virus is seldom present in pig's urine. Human to human infection has been recorded on many occasions. Unprotected close contact with infected patients has resulted in infection in health care providers. While it is not well understood as to how long the virus can survive in hospital environment including floors, bed railings and fomites, their role in transmitting the virus cannot be ignored. In fact, there is limited data even on the persistence of $\mathrm{NiV}$ in body fluids/tissues and also on partially eaten bat fruits and in date palm sap and in drinking water sources.

The incubation period is usually 4 to 14 days, but can be as short as 2 days or may be as long as 45 days. In many patients the infection is asymptomatic. Both pigs and humans may be infectious during the incubation period. In humans, the initial symptoms simulate flu like illness with fever, headache, malaise, which may be followed by disorientation and coma. Acute encephalitis may soon develop usually resulting in high mortality. In focal sporadic cases mortality may be $100 \%$. From 1998 to 2015, there have been about 600 cases of NiV human infection. The mortality in outbreaks in India and Bangladesh ranged between 43 and $100 \%$. Some survivors of $\mathrm{NiV}$ infections may have late neurological complications like seizures and personality changes. Relapses also occur in some patients after initial recovery. When encephalitis develops months after initial contact with the virus, the specific diagnosis becomes more difficult. The MRI brain may be helpful in these patients. The virus can be isolated from kidneys, CSF and other body tissues including liver, but most laboratories depend on ELISA, RT-PCR and immunofluorecent tests. The treatment is largely symptomatic and supportive. Ribavirin, Chloroquin and human monoclonal antibodies have been used but their beneficial effect is not well established. Recently there is some optimism that new antihepatitis $\mathrm{C}$ virus drugs may be useful in $\mathrm{NiV}$ infection, but it is too early to comment on. Chronologically tracking NiV epidemics, it appears that initial cases of infection started in pigs and humans from Northern Malaysia in September 1998 and due to transportation of pigs to Southern Malaysia and importation of pigs by Singapore, the epidemic spread to these regions in late 1998 and early 1999. The infection in early phases was thought to be Japanese virus encephalitis but a thorough virological analysis revealed that it was a new virus and was named Nipah Virus (NiV) after the name of the village in Northern Malaysia from where the first cases were reported. Proper education and preventive measures taken in Malaysia and Singapore including culling of over one million pigs and closing of abattoirs resulted in containment of the epidemic. No more epidemics have been reported form Malaysia or Singapore after the first epidemic in 1998-1999. By the turn of the present century in February 2001, another $\mathrm{NiV}$ epidemic was reported from Siliguri, West Bengal, India but was transmitted by infected bats and no intermediate/amplifier hosts (pigs) were involved. A couple of months later in April/May 2001, a similar bat transmitted epidemic was reported from Meherpur, Bangladesh. Thereafter almost every year or every alternate year, NiV epidemics have been reported from several towns/districts of Bangladesh. In April 2007, another NiV epidemic was reported from Nadia, West Bengal, India. The latest NiV epidemic in the second half of May 2018 which involved two northern districts of Kerala State, India resulted in 16 fatal cases. The epicentre of this outbreak was in Kozhikode district with a few cases recorded in the adjoining Malappuram district. At the time of writing this editorial the 
authorities claim that the present epidemic is controlled but the occurrence of more cases cannot be ruled out with certainty as the disease incubation is variable. We need to wait till double the incubation period of the infection agent is over from the last reported case to be sure that the spread of the $\mathrm{NiV}$ is controlled in the present epidemic. However, it seems that the health authorities have taken all the timely and scientific measures in Kerala to halt the epidemic. Bats are the main reservoir hosts involved in transmitting $\mathrm{NiV}$ in Bangladesh and India unlike Malaysia and Singapore where the infection was mediated through infected pigs. Genetically, the NiV strain causing epidemics in Bangladesh and India appears to be different from Malaysia and Singapore strain. It appears that NiV has made Bangladesh its home country and the virus is widely distributed in bat population there resulting in epidemics almost every year. The epidemics in Bangladesh and India may have seasonal variations. Loss of natural habitats due to urbanization, deforestation, extreme variation in climatic conditions including heavy rains and storms may lead to increased virus load in bats and the virus may spill out in their urine and saliva. The partially bat eaten fruits and the bat contaminated drinking water sources have been thought to transmit the virus. At times virus contaminated date palm sap has been held responsible for indirect transmission of $\mathrm{NiV}$ to humans [2]. Human to Human transmission of $\mathrm{NiV}$ is also well established [3].

There has been some progress in developing a protective vaccine in the recent past. A recombinant subunit vaccine formulation protects against the lethal $\mathrm{NiV}$ challenge in cats [4]. Earlier, another vaccine called ALVAC Canarypox vectored Nipah F and G vaccine was quoted to be a promising vaccine for swine with a potential for humans as well [5]. The development of an effective vaccine against $\mathrm{NiV}$ has been hampered partially because of some inherent limitations. NiV is an RNA virus besides being a zoonotic infection. The mutations in RNA viruses which cause zoonotic infections occur at very high frequencies. Given the fact that at present we have neither any recommended vaccine nor there are any antiviral drugs for $\mathrm{NiV}$, the only options are some general preventive measures and intensive supportive therapy guidelines to be followed to mitigate the epidemics. These measures include mass education at all levels about the $\mathrm{NiV}$, avoidance of contact with bats and pigs and their secretions and excreta and ensuring that these animals do not lick or contaminate foods, drinks and drinking water supplies. People should be advised not to consume any vegetables or fruits partially eaten by bats. Drinking of date palm sap contaminated by bats should be discouraged. As both infected patients and bodies of fatal cases contain $\mathrm{NiV}$, the contact with them should be avoided. No rituals like spraying, washing and embalming of dead bodies should be undertaken. Burials and cremations of dead bodies should be done by well trained staff who would meticulously use Personal Protective Equipment (PPE) on the same analogy as for Ebola virus. Animal carcasses should be safely disposed of as per standard protocol. Quarantine measures should be taken as per requirements for patients and their close contacts. $\mathrm{NiV}$ is a Category $\mathrm{C}$ bioagent and the Biosafety Level 4 is recommended for laboratories engaged in diagnosis of NiV. A good coordination between medical and veterinary departments is required to contain the epidemics. There should be a well-documented medical department surveillance protocol in place about zoonotic viral infections especially for the ones which carry high fatality. Lack of preparedness will lead to large epidemics. NiV has the potential to cause pandemics [6]. The interest in $\mathrm{NiV}$ has remained limited to small research communities and affected countries but its control needs more than R\&D [7]. Viruses like NiV, Ebola and Zika should be given priority for research projects. It is relevant to mention here that another paramyxovirus, the Cedar virus (a non-pathogenic virus) which is closely related to $\mathrm{NiV}$ and Hendra virus has recently been isolated from bats in Australia. There is some hope that a critical analysis of host-parasite interactions in Cedar virus, $\mathrm{NiV}$ and Hendra virus may delineate the missing links and the results thus obtained may be exploited for development of an effective vaccine and also the antiviral drugs against the $\mathrm{NiV}$.

\section{References}

1. Outbreak of Hendra-like virus-Malaysia and Singapore, 1998-99 (1999) Morb Mort Weekly Rep 48: 265-269.

2. Luby SP, Rahman M, Hossain MJ, Blum LS, Husain MM, et al. (2006) Foodborne transmission of Nipah virus, Bangladesh. Emerg Infect Dis 12: 1888-1894.

3. Gurley ES, Montgomery JM, Hossain MJ, Bell M, Azad AK, et al. (2007) Person-to-person transmission of Nipah virus in a Bangladeshi community. Emerg Infect Dis 13: 1031-1037.

4. McEachern JA, Bingham J, Crameri G, Green DJ, Hancock TJ, et al. (2008) A recombinant subunit vaccine formulation protects against lethal Nipah virus challenge in cats. Vaccine 26: 3842-3852.

5. Weingartl HM, Berhane Y, Caswell JL, Loosmore S, Audonnet JC, et al. (2006) Recombinant Nipah virus vaccines protect pigs against challenge. J Virol 80: 7929-7938.

6. Luby SP (2013) The pandemic potential of Nipah virus. Antiviral Res 100: 38-43.

7. Nipah virus control needs more than R \&D (2018) The Lancet 391: 10137. 